\title{
Ecomorphological implications of the microstructures on the tongue of the fawn roundleaf bat, Hipposideros cervinus (Chiroptera : Hipposideridae)
}

R. S. K. Sharma, M. K. Vidyadaran, I. Zulkifli, J. Mohd Azlan, S. Sumita, A. J. Azilah and O. K. Ho

Australian Journal of Zoology 47(4) 405 - 409

Published: 1999

\section{Abstract}

The morphology of the lingual papillae on the tongue of the fawn round-leaf bat (Hipposideros cervinus) was studied by scanning electron microscopy to determine its functional role in feeding ecology. Both mechanical and gustatory papillae were detected on the lingual surface. Large pronged papillae at the lingual apex provide a rake-like surface that facilitates quick retrieval of insect prey that may be trapped by the wing and tail membranes. These papillae also provide additional traction and act as a barrier, preventing the insects from escaping. Additional securing and gripping structures include the crowned filiform papillae situated on the anterior half of the tongue. Conical papillae on the lateral and medial aspects of the lingual root serve as a protective barrier to the lingual mucosa, and aid in directing insect fragments towards the oesophagus. The pair of small vallate papillae at the lingual root may reflect a compromise in gustatory potential. Taste perception may be a secondary feature in food selection of this bat and fungiform papillae may resume a more important mechanical function. Collectively, the lingual papillae of $H$. cervinus portray an adaptation to mechanical manipulation of food, instead of taste perception, which may not be of primary importance to insect feeders.

https://doi.org/10.1071/ZO98051

(C) CSIRO 1999

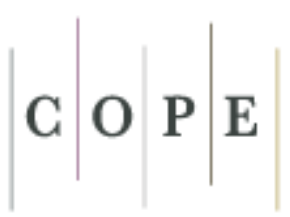

JM12789

Buy PDF $\$ 25.00$

Export CitationCited By (4) 